\title{
Decreased Sensitivity to Phonemic Mismatch in Spoken Word Processing in Adult Developmental Dyslexia
}

\author{
Esther Janse • Elise de Bree - Susanne Brouwer
}

Published online: 20 April 2010

(C) The Author(s) 2010. This article is published with open access at Springerlink.com

\begin{abstract}
Initial lexical activation in typical populations is a direct reflection of the goodness of fit between the presented stimulus and the intended target. In this study, lexical activation was investigated upon presentation of polysyllabic pseudowords (such as procodile for crocodile) for the atypical population of dyslexic adults to see to what extent mismatching phonemic information affects lexical activation in the face of overwhelming support for one specific lexical candidate. Results of an auditory lexical decision task showed that sensitivity to phonemic mismatch was less in the dyslexic population, compared to the respective control group. However, the dyslexic participants were outperformed by their controls only for word-initial mismatches. It is argued that a subtle speech decoding deficit affects lexical activation levels and makes spoken word processing less robust against distortion.
\end{abstract}

Keywords Dyslexia - Lexical activation - Spoken word recognition · Speech processing · Phonological deficit

\section{Introduction}

When spoken words are long and thus contain more redundant information, recognition is normally highly robust against distortions of external noise or accidental mispronunciations. Small mispronunciations may go unnoticed and may be immediately restored by the listener (Cole 1973; Marslen-Wilson 1985). As long as the remaining speech signal is unambiguous with respect to lexical identity, distorted or missing speech sounds are not necessarily problematic for spoken word processing either (Samuel 1987; Warren 1970). Nevertheless, even though small mispronunciations in words may (hardly) be noticeable in the context of a

E. Janse $(\bowtie) \cdot$ E. de Bree

Utrecht Institute of Linguistics OTS (Utrecht University), Janskerkhof 13, 3512 BL Utrecht,

The Netherlands

e-mail: esther.janse@mpi.nl

E. Janse $\cdot$ S. Brouwer

Max Planck Institute for Psycholinguistics, Nijmegen, The Netherlands 
whole sentence, more and more evidence has accrued that (initial) lexical activation depends on the goodness of fit between the presented speech signal and the stored mental representation of the target word. Deviations from the target form are translated into reduced amounts of lexical activation for that same target. Strong evidence for gradedness in lexical activation comes from studies by Connine (1994); Connine et al. (1997) and Frauenfelder et al. (2001), in which the effect of phonemic mismatch on phoneme detection time was investigated. Lexical activation is assumed when faster detection times are found for e.g., target phoneme /1/, when participants are presented with auditory 'focabulary' (for 'vocabulary', but now with a word-initial mismatch) than when they are presented with a non-word like 'satobulary' which is not a close match to an existing word: the faster response time to /l/ in the first case must be due to activation of the word 'vocabulary'. By varying phonetic distance and position of the mismatching phoneme, it can be investigated to what extent this mismatch leads to gradual decreases in lexical activation. Studies on more subtle deviations from the target form have shown that even fine phonetic detail is translated directly into appropriate amounts of activation for the intended target (Andruski et al. 1994; Janse et al. 2007; Mitterer and Ernestus 2006; Salverda etal. 2003; Shatzman and McQueen 2006; Spinelli et al. 2003).

In language-impaired populations, however, this direct translation from bottom-up acoustic evidence to lexical activation may be disturbed, either because sound processing is hampered, because the process of mapping speech to the lexicon is impaired, or because the lexical representations themselves are less clearly specified. Developmental dyslexia, a languagebased disorder characterised by difficulties in reading and/or spelling that are unexpected in relation to cognitive abilities and age (Lyon 1995), is often diagnosed in childhood, but persists into adulthood. It is widely accepted that developmental dyslexia is a neurological disorder with a genetic origin which mainly surfaces as a phonological deficit.

The phonological deficit hypothesis (Ramus 2003; Snowling 2001) holds that there is an impairment in the phonological processing system of people with dyslexia, rendering poor construction, maintenance, and retrieval of phonological representations. These phonological representations are essential for reading development, because they facilitate phonological awareness and the development of sound-to-symbol correspondences. Some studies have specified this phonological deficit by arguing that it is due to a more general and low-level deficit in auditory processing: processing rapidly changing auditory information would be problematic for dyslexic listeners (e.g., Talcott et al. 2002; Tallal 1980, 1984). The question of whether the sound processing problems are general or speech-specific has been a matter of ongoing debate (e.g., Blomert et al. 2004; Mody et al. 1997; Nittrouer 1999; Ramus et al. 2003). The auditory temporal processing account of dyslexia is challenged by the observation that none or only a minority of people with reading problems exhibit auditory deficits, that there is little or no relationship between the severity of the auditory deficit and the phonological deficit and the observed reading problems, and that treatment of a auditory processing deficit does not improve literacy or language abilities (see McArthur et al. 2008; Rosen 2003 and Vellutino et al. 2004, for reviews).

In contrast to a low-level auditory processing deficit, it has also been proposed that the phonological deficit in dyslexia is caused by problems with extracting (and processing) discrete phonological representations from the speech signal, rather than as generally poorer auditory perception (e.g., Manis et al. 1997; Ramus 2003; Serniclaes et al. 2001). Either way, the neurological basis for these phonological problems is in the speech processing areas of the brain (e.g., Paulesu et al. 1996).

Importantly, even though there is now a host of studies on speech processing in dyslexia, it has hardly been investigated how their 'phonological deficit' affects online spoken word processing. Little is known about the translation of bottom-up acoustic evidence to activation 
of lexical candidates in people with dyslexia. There are some studies on lexical processing in dyslexic children. Two gating studies showed that dyslexic children require more phonological information to identify spoken words accurately (Metsala 1997; Metsala and Walley 1998). Furthermore, Carroll and Snowling (2004) examined performance of 4-to-6-years-old children with a familial risk of dyslexia, i.e., children with at least one dyslexic parent, and control children on a mispronunciation detection task. The words were mispronounced by substituting a single consonant phoneme in word-initial (e.g., $\underline{n} u c k$ for $\underline{d} u c k$ ), word-medial (e.g., golilla for gorilla) or word-final (e.g., moush for mouse) position. There was a significant group effect, with the at-risk children scoring significantly lower than their age-matched controls. Results were not provided for the different word and syllable positions. Van Alphen et al. (2004) also investigated children at-risk of dyslexia on a mispronunciation detection task in which the word-initial mismatches were either minimal (only wrong place of articulation of the consonant; e.g., vebra for zebra 'zebra') or maximal (place of articulation, manner and voicing were wrong, e.g., pebra for zebra). All participants made more correct detections in the maximal than in the minimal condition, but the at-risk children showed more difficulty in detecting small/minimal phonological mispronunciations than controls.

There is evidence that processing of sound information remains problematic in adults with dyslexia (Felton et al. 1990; Paulesu et al. 2001; Pennington et al. 1990; Szenkovits and Ramus 2005). If adult dyslexics have a speech sound processing impairment, their impaired processing of incoming acoustic information may delay the activation of lexical candidates for word recognition. This is in line with the gating studies (mentioned above) showing that dyslexic children required more phonological information to identify spoken words accurately than their normal-reading controls (Metsala 1997; Metsala and Walley 1998). When presented with correctly pronounced words, we assume that adult dyslexic participants face an initial delay in lexical activation, relative to non-dyslexic listeners, but gradually zoom in on the target word. It is important to state that speech processing in dyslexia may not just be delayed, relative to normal-reading peers, but subtle speech processing problems may lead to inappropriate amounts of lexical activation (such as 'overactivation'). The present study focused on mispronounced words to investigate whether lexical activation in dyslexic adult listeners is equally sensitive to phonemic mispronunciations in longer spoken words (e.g., in a pseudoword such as procodile) as in a control group of age- and education-matched listeners. A similar approach was taken in a study on lexical activation in aphasic listeners (Janse 2010). Even though the two language pathologies are very different in terms of cause and severity, we had the opportunity to test the two groups with the same language materials. This allowed a comparison of the results: not only in quantitative terms (performance difference between control and pathological group), but also in qualitative terms (do the pathological groups differ in what they find most difficult, relative to their respective control groups). Longer pseudowords were used to investigate situations in which there is actually only one possible lexical candidate left and in which either the word-initial or word-final phoneme is changed. This allows us to assess the fine-tuning of the auditory lexical recognition system in dyslexia: to what extent does segmental mismatching information affect the strength by which a lexical candidate is activated, in the face of overwhelming evidence for one specific lexical candidate? This fine-tuning of the lexical processing system in dyslexia is tested by having a one-feature difference between the target and mismatching phoneme (voicing, manner, or place of articulation) and by manipulating whether the mismatching phoneme occurred either in a stressed or unstressed syllable. A phoneme change in an unstressed syllable was obviously expected to be less salient (relative to the target word) than a change in a stressed syllable (see Bowey and Hirakis 2006). 
It deserves further attention to assess whether lexical activation problems will be found across-the-board in dyslexic listeners, regardless of the position of the phonemic mismatch. On the basis of a phonological processing deficit, one might expect to find listener group differences in lexical activation upon presentation of pseudowords both if the mismatch occurs in initial and in final position. Nevertheless, it is possible that people with dyslexia mainly show a deviant activation pattern, compared to the control group, on word-initial mismatches. Two lines of evidence have been provided to support this prediction; first, the importance of initial position for spoken word recognition, and secondly, short-term memory problems in people with dyslexia.

With respect to the importance of the word-initial sound, it has been found that analysis of the first arriving sounds serves to activate an initial pool of potential word candidates in spoken word comprehension, (e.g., Gaskell and Marslen-Wilson 1997; Norris 1994). Information that comes later will narrow down the set of possibilities until one winning candidate is left. An impaired sound analysis may be more problematic for pseudowords with a mismatching phoneme in word-initial than in word-final position. Upon presentation of the initial fragment of a spoken word containing a changed phoneme (e.g., procodile for crocodile), the word-initial "pro"-fragment would yield reliable activation for multiple word candidates starting with "pro" in the normal-reading control group. Upon presentation of this same initial fragment, the dyslexic listeners may be slower in decoding such that there is no firm evidence yet for lexical candidates starting with either 'pro' or 'cro'. When more of the pseudoword becomes available, both listener groups will gradually zoom in on this one particular lexical candidate, granted that dyslexic participants may need more information than control participants to recognise a word. Once past the theoretical uniqueness point, evidence converges for this one specific target, despite the initial word fragment. Importantly, however, whereas normal-reading control listeners can still go back to an acoustic trace of the initial mismatching phoneme, dyslexics' impaired speech analysis does not provide strong counterevidence concerning the identity of the mismatching phoneme to speak against the evidence for this one particular lexical target. Consequently, in the absence of firm counterevidence, lexical activation for this one candidate continues to build up in the dyslexic listeners.

Secondly, the expectation of different performance on perceiving mismatching words with mismatching initial or final consonants can also be phrased in terms of short-term memory or phonological processing. Studies on non-word repetition problems in dyslexia (e.g., De Bree et al. 2007; Muter and Snowling 1998; Ramus et al. 2003; Roodenrys and Stokes 2001) have shown that short-term memory and phonological processing is impaired in dyslexia: sound information that does not contact the lexicon fades relatively quickly. This means that it will be difficult for dyslexic listeners to go back to the trace of the word-initial fragment in case there has been a revision of the appropriate candidate pool. The initial phoneme did not provide bottom-up support for the real word target, yet this can be overruled by later arriving 'convincing' evidence, in particular if there is no (reliable) trace left of the actually presented fragment.

Thus, even though a speech decoding deficit in dyslexia should in principle yield problems with both word-initial and word-final mismatching phonemes, performance differences between dyslexic and control participants might be smaller for final positions because the latter allow for a 'checking procedure'. Once listeners are past the theoretical uniqueness point, they can direct their attention towards checking the remaining incoming speech information against the already activated lexical representation.

For final mismatch pseudowords, this means that they only have to check the sound form of this specific target word (cabinep) to their stored representation (cabinet). With word-initial mismatches, there are no representations to compare the speech material to yet. In a set-up 
in which listeners know that some of the lexical material contains phonemic errors, dyslexic listeners may be able to compensate for their speech decoding and processing problem if they can direct their attention to this 'checking' procedure. Thus, if dyslexic listeners employ this strategy, then word-final mismatches should be detected more often than word-initial mismatches.

In sum, the present study aimed to test the following hypotheses.

1. Sensitivity to phonemic mismatch in spoken polysyllabic pseudowords is lower in dyslexic adult listeners than in a control group of age-matched listeners. This will translate into higher-than-appropriate levels of lexical activation in the dyslexic group upon presentation of pseudowords.

2. Dyslexic listeners may be able to compensate for their speech decoding problem (and thus for their reduced sensitivity to mismatching information) if they can direct their attention to a checking procedure: checking the incoming speech sounds to one specific lexical candidate's representation. Differences between dyslexic and control listener groups are therefore expected to be greater for mismatches in word-initial position than word-final position.

\section{Method}

Speeded lexical decision was chosen as a task reflecting lexical activation upon presentation of auditory input, instead of, for example, the phoneme detection task mentioned in the "Introduction", because of the simplicity of the lexical decision task as opposed to an orthography-related task. When the number of participants is relatively low (as is often the case in pathological studies), within-participant designs are desirable, which also ruled out tasks as (semantic) priming paradigms with blocked designs (to avoid repetition of the same target).

Studies on the effects of lexical neighbourhood density on non-word processing (Luce and Pisoni 1998; Vitevitch and Luce 1999) have shown that lexical decision performance reflects lexical activation levels upon auditory input. Non-words with many neighbours (similarsounding words) in the lexicon result in more activation at the lexical level than non-words that have fewer neighbours. The more lexical activation a non-word evokes, the more difficulty listeners will have in deciding that the presented item is not a word. Lexical decision performance was therefore taken as an appropriate measure of lexical activation upon presentation of non-words. As an additional advantage, the task offers both accuracy and response time data, which allows us to focus on response time data, as a measure of processing time, if hardly any errors are made.

Lexical activation was assessed by studying lexical decision performance upon presentation of a pseudoword (e.g., fáprika), compared to that upon presentation of a non-word without obvious lexical resemblance (fákarip) for an existing word (here, páprika 'paprika'). In this way, accuracy and response time can be compared in two NO-response conditions ("no, this is not a word in my language"). The larger the difference between the two conditions, the more lexical activation is assumed for the pseudowords. In other words, overactivation, or being relatively insensitive to phonemic mismatch, translates either in incorrect YES-responses or in slow NO responses.

\section{Participants and Selection Procedure}

Twenty-one adults with dyslexia and 21 control participants were tested. Mean age was 30 (range 21-62) years for the dyslexic participants and 27 (range 19-66) years for the controls. 
Table 1 Reading battery scores for the two participant groups

\begin{tabular}{llllrr}
\hline & \multicolumn{2}{l}{ Dyslexic adults } & & \multicolumn{2}{l}{ Control adults } \\
\cline { 2 - 3 } \cline { 5 - 6 } & Mean & SD & & Mean & SD \\
\hline One-Minute-Test (max. score 116) & 78 & 16 & 104 & 12 \\
Klepel (max. score 116) & 71 & 22 & 3 & 107 & 7 \\
Non-word repetition (max. score 48) & 43 & 4 & 21 & 2 \\
Verbal competence (max. score 26) & 19 & & & 26 \\
\hline
\end{tabular}

Apart from age-matching, gender ( 9 male and 12 female participants in both groups) and educational level in the two groups were matched as closely as possible. All participants were native speakers of Dutch with no reported history of hearing problems. In addition to these criteria, in order to be included in the dyslexic group, participants had to show poor performance on tasks of the Dutch reading test battery (Kuijpers et al. 2003).

Prior to the auditory lexical decision experiment, four screening tasks of the Dutch reading test battery were administered: (1) Een-Minuut-Test (One-Minute-Test for timed reading of words, Brus and Voeten 1973); (2) De Klepel (a two-minute pseudoword reading test, Van den Bos et al. 1994); (3) a non-word repetition task (De Jong 1998). Finally, a verbal competence task (Analogies) taken from the Dutch version of the Wechsler Adult Intelligence Scale was administered (Wechsler 2000). This reading test battery took about 15 minutes.

Dyslexic participants had to show poor performance on all the tasks, except the verbal competence task, as this is often a relative strength for (higher educated) people with dyslexia, in contrast with their reading and spelling abilities. Additionally, more strict terms were applied in that performance on the EMT or Klepel had to be $<10$ th percentile, or $<25$ th percentile on both the EMT and Klepel, and a discrepancy of at least $60 \%$ between verbal competence and performance on the EMT and Klepel (based on Kuijpers et al. 2003). This cut-off based on speeded reading ensures that the participants had persistent (and severe) literacy difficulties. No attempt was made to look at different profiles/subtypes of dyslexia, as the assumption was that potential difficulties with spoken word processing would surface regardless of performance on other cognitive measures.

In Table 1, mean raw test scores for the adults with and without dyslexia are presented. Statistical differences between the two groups were found on the One-Minute-Test $(t(40)=$ 5.86; $p<0.001)$, the Klepel test $(t(40)=7.12 ; p<0.001)$, and the non-word repetition task $(t(40)=3.75 ; p=0.001)$. Performance on the verbal competence task did not reveal a significant difference between the two groups $(t(40)=1.83 ; p=0.08)$. The reading and non-word task results show a clear distinction between the two groups.

\section{Materials}

The Dutch language material consisted of 40 mismatch pseudoword items (e.g., figa'ret for sigaret 'cigarette'), 40 non-word control items (e.g., non-word pego'leen) and 70 'real words (as fillers, e.g., abrikoos 'apricot'). The material was a subset of the material used in a similar study on sensitivity to phonemic mismatch in aphasia (Janse 2010). Since the speech processing deficit was assumed to be less severe in dyslexia than in aphasia, we only investigated the minimal-mismatch conditions in the present study (and left out pseudowords in which the phonemic mismatch involved more than one phonetic feature). The non-word items were all 
Table 2 An overview of the conditions with stimuli examples

\begin{tabular}{lllllll}
\hline & \multicolumn{2}{l}{ Initial mismatch } & & \multicolumn{2}{l}{ Final mismatch } \\
\cline { 2 - 3 } \cline { 5 - 6 } & Pseudoword & Control & & Pseudoword & Control \\
\hline Stressed syllable & fáprika & fákarip & & krokodír & geufadír \\
Unstressed syllable & symnastíek & simtiesnáak & salárif & losóerif \\
\hline
\end{tabular}

phonotactically legal in Dutch. Each item had three or four syllables. The pseudoword items differed on two aspects: position of the phoneme mismatch, and whether or not the syllable containing the mismatching phoneme had main lexical stress. It makes sense that the greater the acoustic/perceptual difference between the changed and canonical word form, the greater the possible effect on immediate lexical activation.

Of the 40 pseudowords, 20 had a phonemic mismatch in word-initial position (e.g., droccoli for $\underline{\text { broccoli }}$ 'broccoli') and 20 had a word-final mismatch (e.g., salarif for salaris 'salary'). Because the pseudowords were relatively long, the mismatch occurred after the theoretical uniqueness point (or, for the initial mismatches, the remaining lexical evidence also converged to one specific lexical item). As said, the altered phonemes constituted a minimal mismatch (e.g., symnastíek for gymnastiek 'gymnastics') in which only place of articulation, manner, or voice was altered. Note, however, that Dutch has final devoicing, so that only place and manner could be modified in final position. Within these categories of 20 items, half of the items (10) had mismatching information in the syllable with main lexical stress (e.g., dróccoli for bróccoli 'broccoli'), and half (10) had the mismatching information in an unstressed syllable (e.g., pelefóon for telefóon 'character'). This was a manipulation of mismatch salience: mismatching phonemes were expected to be more salient as mismatches when they occurred in lexically stressed than unstressed syllables.

For each pseudoword, a control non-word was composed, which shared as many phonemes as possible as its pseudoword counterpart (e.g., fákarip from fáprika for paprika 'paprika'). However, the phonemes in this control non-word were placed in a different order to avoid lexical resemblance. Table 2 provides an overview of the non-word conditions; a complete list of all non-word items is provided in "Appendix 1".

The 80 non-word stimuli, plus 70 real words as fillers, and an additional 12 practice stimuli, were recorded by a female speaker of standard Dutch (second author). Each item was stored as a separate sound file, and downsampled to $32 \mathrm{kHz}$. The pseudowords had a mean duration of $789 \mathrm{~ms}(\mathrm{SD}=94)$. In order to match pseudowords and control non-words as closely as possible (apart from lexical resemblance obviously), the control non-words were time-scaled by way of PSOLA time-compression or expansion, to the exact same duration as their pseudoword counterparts.

\section{Procedure}

The experimental software programme TEMPO (Motta et al. 2000) was used to present the participants with the stimuli in a random order. The material was presented in four blocks, preceded by a practice block of 12 stimuli (eliciting both YES and NO responses) to familiarise the participants with the task and the speech material. Participants were informed that they could pause in between the blocks. The speech materials were presented at a clear but comfortable loudness level (as judged by the experimenter) and was kept constant for all participants. Participants wore sealed headphones and were asked to respond as 
fast as possible, without sacrificing accuracy. Following item onset, there was a 3 second window in which the response could be given. After $4 \mathrm{~s}$, the next item was presented. Participants could choose whether they used one or two hands to press the YES and NO buttons.

\section{Results}

Lexical decision accuracy and response time (measured from word onset) were investigated to compare lexical activation upon presentation of pseudowords and matched control non-words. Accuracy and response time were thus compared in two NO conditions (no, this is not a word in my language) within the two test populations. This approach would allow us to gain insight into the difference in response times between the groups in an 'easy' condition without lexical resemblance and a more challenging condition (the pseudowords). The results for the non-words were analysed for the effects of Participant Group (control or dyslexic); Non-word Type (pseudoword or control non-word); Mismatch Position (word-initial or word-final), and Metrical salience (stressed or unstressed syllable).

Accuracy rates and response times will be discussed separately.

\section{Accuracy Data}

Accuracy rates were arcsine-transformed (as is customary for proportional scales) and analysed (by participants and by items) to investigate the effects of all between-, within-participants and within-items factors mentioned above. The results of these analyses are provided in "Appendix 2". Overall lexical decision accuracy in the mismatch pseudoword conditions was 95\% for the control adults and $93 \%$ for those with dyslexia. For the control non-words, mean accuracy was $99 \%$ for the control adults and $100 \%$ for the dyslexics. This shows that accuracy is high for both participant groups. The effect of Non-word Type was significant by participants and by items $\left(F_{1}(1,40)=153.60, p<.001 ; F_{2}(1,36)=7.29, p=.011\right)$, indicating that both groups reached lower scores on the mismatch than the control non-word items. The overall effect of Participant group was not significant $\left(F_{1}(1,40)<1\right.$, NS; $F_{2}(1,36)<$ $1, \mathrm{NS})$, but the interaction between Non-word Type and Participant group approached significance $\left(F_{1}(1,40)=3.22 ; p=.081 ; F_{2}(1,36)=5.53, p=.024\right)$. This indicates that the accuracy difference between mismatch and control items was larger for the dyslexic adults than for the controls.

More detail on the conditions that were relatively difficult for the dyslexic participants is given in Fig. 1. Since both groups scored $99-100 \%$ in all control conditions, these conditions were not included in the figure.

The statistical analyses showed two further results involving Participant Group: the significant interaction of Participant Group $\times$ Non-word Type $\times$ Mismatch Position $\left(F_{1}(1,40)=\right.$ $\left.8.25, p=.006 ; F_{2}(1,36)=6.39, p=.016\right)$. This can be seen in Fig. 1: the dyslexic participants mainly perform worse than the controls when the mismatch is in initial position. None of the other interactions involving Participant Group were significant. This interaction was checked in post hoc tests (Bonferroni corrected). For the pseudoword condition with mismatches in word-initial position, the control group significantly outperformed the dyslexic group ( $p=.054$ by subjects and $p=.003$ by items). At the same time, in the control non-word condition (the control non-words to the initial mismatch pseudowords), dyslexic participants (100\% correct) outperformed the control group who had $99 \%$ correct $(p=.036$ 


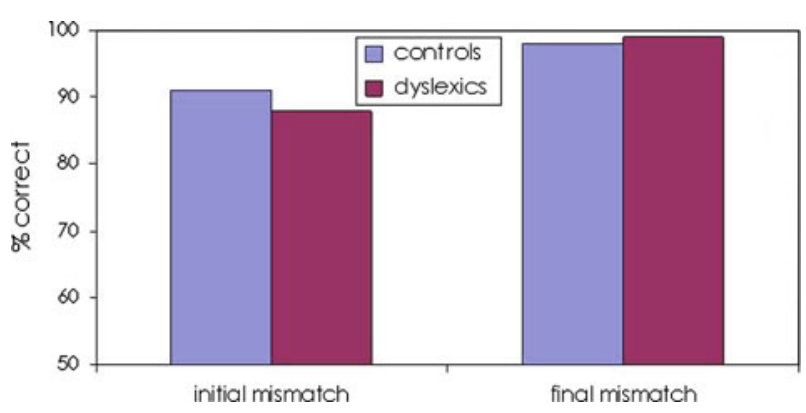

Fig. 1 Mean accuracy rate in different mismatch conditions (all pseudowords) for the two groups

by subjects and $p=.034$ by items). In other words, given the dyslexic participants' very accurate performance on the control non-words, their slightly decreased performance on the pseudowords with word-initial mismatch, relative to the control group, comes out more clearly. These results can then be accounted for by decreased sensitivity to mismatch in word-initial position in the atypical group.

Now that the results have shown a greater difference between the groups for the mismatches in word-initial than word-final position, it is interesting to assess which minimal mismatches proved most difficult for the dyslexic participants (but note that voicing, place of articulation and manner were not distributed equally over the minimal mismatches). Performance between dyslexic and control listeners did not differ for the initial mismatch items in which voicing was manipulated, but involved more errors in the categories of place (controls: 99\%; dyslexics: 96\%) and manner of articulation (controls: 92\%; dyslexics: 87\%). This indicates that the dyslexic adults' poorer performance for initial mismatches in particular could not be attributed to voicing (which in Dutch can only be manipulated in word-initial position).

\section{Response Time Data}

Additionally, response times (converted to 1/RT values) were analysed by participants (nested under Participant Group) and by items (nested under Mismatch position and Metrical Salience). Mean response time (measured from non-word onset) in the mismatch and control conditions is given in Fig. 2. The results of the ANOVAs are presented in "Appendix 3".

There were significant main effects of Participant Group and Non-word Type. This indicates that the dyslexic participants were slower across the board $\left(F_{1}(1,40)=12.42\right.$, $\left.p=.001 ; F_{2}(1,36)=578.67, p<.001\right)$ and that all participants were slower to reject pseudowords than control non-words $\left(F_{1}(1,40)=155.83, p<.001 ; F_{2}(1,36)=56.35\right.$, $p<.001)$. Additionally, the interaction between Participant Group, Non-word Type and Mismatch Position was significant $\left(F_{1}(1,40)=8.08, p=.007 ; F_{2}(1,36)=3.94\right.$, $p=.055$ ). This can be seen in Fig. 2 (note that RTs were measured from word onset): whereas control listeners were clearly faster at rejecting initial mismatch pseudowords than those with a final mismatch, this position effect was smaller for the dyslexic listeners (relative to the respective control conditions). Critically, the response time data confirm the increased difficulty the dyslexics have with the initial mismatch pseudowords. 


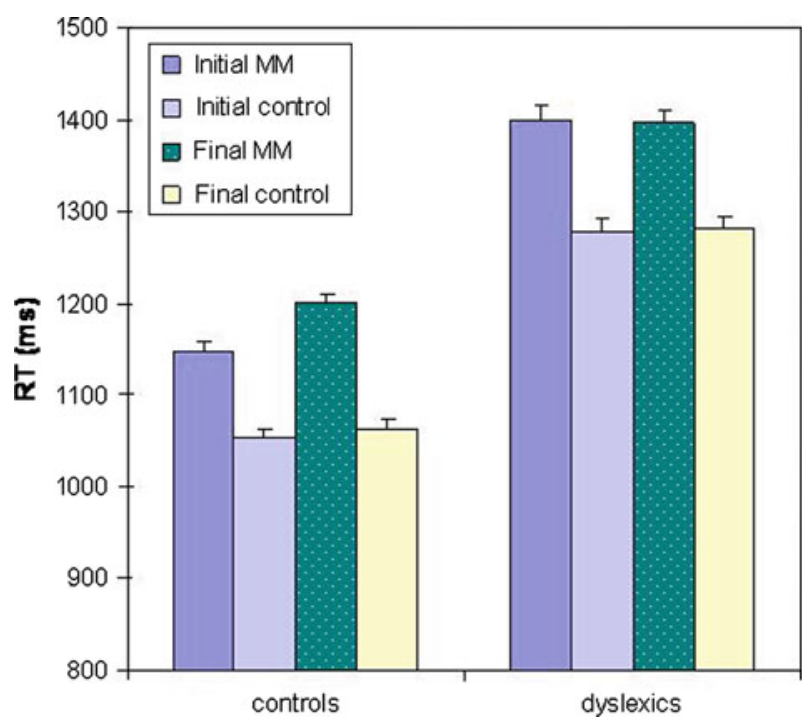

Fig. 2 Mean response time (in ms) to mismatch (pseudowords) and control non-words, broken down by mismatch position

\section{Discussion}

This study aimed to investigate the effect of phonemic mismatch on lexical activation in dyslexic listeners. If the process of mapping incoming sound to the lexicon is disturbed in this atypical population, lexical activation might be affected less by phonemic mismatch, compared to unimpaired control listeners. Auditory lexical decision performance was studied for pseudowords and control non-words: the pseudowords deviated from polysyllabic real words in only one phoneme, whereas the control non-words were constructed so that they resembled no lexical item in particular. As hypothesised (hypothesis 1), sensitivity to phonemic mismatch was lower in the dyslexic listener group, relative to the control group. Speech processing and mapping of sound to the lexicon is (slightly) disturbed, such that presentation of some pseudowords yielded more lexical activation than actually appropriate. Note, however, that the control participants only outperformed the participants with dyslexia when the phonemic mismatch was in word-initial position, in line with hypothesis 2 . The results of the response time analyses confirmed the accuracy data in that they provided further support for the increased difficulty the dyslexic listeners have with initially mismatching pseudowords. This RT backup is important because any interaction between Participant Group and the material in the accuracy data could be an artifact of the control group's ceiling performance. Additionally, the dyslexic participants were slower overall, which is line with the interpretation that they face an initial delay in lexical activation, relative to non-dyslexic listeners, and demand more time to zoom in on the target word.

Dyslexic adults were thus affected more by mismatch position than controls. The aphasia study using the same materials (Janse 2010) did not show an interaction between listener group (aphasic vs. control) and mismatch position. The aphasia results were characterised better by overactivation upon presentation of pseudowords, regardless of mismatch position. In other words, they had serious difficulty rejecting words with mispronunciations 
in both initial and final position. Again, it should be noted that aphasia affects speech processing to a much more severe extent than dyslexia: the performance difference between the control and pathological group was much greater in Janse (2010) than in the present results. The dyslexic adults did not differ in accuracy from the controls for the final mismatches, which suggests that they could compensate for their subtle speech decoding problems if they had been able to focus on one lexical candidate in particular. Again, note that a rigid interpretation of the phonological deficit account of dyslexia would predict problems with word-like pseudowords across the board. When presented with speech material, dyslexics may face an initial somewhat noisy or fuzzy analysis, but they gradually zoom in on the target word. The actual point at which the word can be distinguished from all other candidates in the lexicon may be situated somewhat later in the word for dyslexic adults than controls. Nevertheless, once (way) past the theoretical uniqueness point, dyslexic adults are also faced with converging evidence for one particular lexical candidate.

For the final mismatch pseudowords, this means that listeners had only one remaining possible word candidate and only had to pay attention whether the sound form of this specific target word (cabinep) matched the stored representation (cabinet). In this condition, the participants thus had to rely on their lexical representations. As argued before, presentation of pseudowords may translate into inappropriate amounts of lexical activation: in the case of a word-initial phonemic mismatch, there is 'overwhelming' evidence for one particular lexical candidate and dyslexics' impaired speech analysis, or in fact their impaired short-term memory/phonological processing, does not provide strong counterevidence concerning the identity of the mismatching phoneme.

Martin and Gupta (2004) proposed that spreading activation is the common process underlying performance of single word tasks (both in word retrieval in production and in speech comprehension) as well as tasks with multiple items such as non-word repetition or repetition span. A speech decoding deficit could be rephrased as an impaired ability to build up a reliable amount of bottom-up information that can be passed on to the level of lexical representations. Any uncertainty about the identity of the initial sounds cannot be resolved later: going back to the phonological representation in auditory memory is less of an option for the dyslexic listeners than for the controls.

In order for this assumed relationship between reliable speech information spreading to the lexical level and measures of verbal short-term memory to hold true, a relationship between performance in the auditory lexical decision task and a measure of verbal short-term memory should be present. Indeed, a moderate and significant correlation is attested between non-word repetition accuracy (taken as a measure of verbal short-term memory, see Table 2) and lexical decision accuracy (collapsed over all mismatch conditions) for the dyslexic participants (Spearman's rho $=.578, p=.006$ ). This moderate correlation between a verbal short-term memory task and lexical decision performance was stronger than found for aphasic patients (Janse 2010). On the basis of these findings, the question arises whether dyslexia is characterised by poor phonological representations or by poor processing of phonological information to achieve lexical access. In the latter case, the phonological representations themselves could be argued to be intact, but they cannot be accessed properly due to limited verbal short-term memory. The debate between a processing or representation deficit in dyslexia is by no means new (see, e.g., Snowling et al. 1986) but has recently been revived (e.g., Blomert et al. 2004; Ramus and Szenkovits 2008). The present findings cannot rule out either viewpoint, as no pure task of representation was presented alongside the auditory lexical decision and verbal short-term memory task. Furthermore, it is difficult to envisage how to tease these two factors apart completely. 
Related to these issues of processing and representation is attention, which is a necessary skill/component for detecting mismatches. It has recently been proposed and found that (Breier et al. 2001; Hazan et al. 2009; Sutcliffe et al. 2006) attentional status contributes to the performance on auditory and speech-specific discrimination tasks, especially for populations with literacy difficulties. The same could be true in the present study. As indicated above, performance of dyslexic and control participants could have been expected to be similar for final positions because these final consonants allow for a "checking procedure', in contrast to mismatches in initial position. When the theoretical uniqueness point of a word has been reached, listeners no longer have discover the word, but can direct their attention towards checking the remaining incoming speech information against the already activated lexical representation. In other words, for targets with final mismatches, processing resources become available as soon as the word is known and this space can be used for error detection. This is much more difficult for a word with a mismatch in onset position, which also demands attention. Unfortunately, no measure of attention was included in the test battery to assess whether and how much attention impacted on performance.

Phonological representation, phonological processing, and attention are all demanded during the reading process. Impoverished lexical entries complicate word recognition during reading, requiring more processing and attentional resources to decode the words to be read. For adult readers, the ongoing difficulties in forming correct phonological representations added with limited reading experience will further affect (fast) word decoding. This will be especially true for longer words that reach the uniqueness point late, unfamiliar, infrequent, or misspelled words or word in a different language.

The present results raise the question how lexical activation builds up for these longer pseudowords in which the degradation is not subtle but involves a phonemic 'error'. In other words, the time course of lexical activation upon presentation of mismatch nonwords, such as procodile or cabinep, would be an interesting issue for investigation. A more direct and continuous measure of lexical activation, such as the eye-tracking paradigm (Cooper 1974; Tanenhaus et al. 1995), might be a better choice than, for example, a semantic priming paradigm with target presentation at various points from word onset. This method has been used successfully, for example, in the investigation of word recognition abilities of 3-years-old at-risk children (De Bree et al. 2008). An additional point to take into account in future research is to compare lexical activation elicited by the maximal non-word procodile to that of the target word crocodile itself, rather than to control non-words that resemble no lexical item in particular, as was done in the present study.

This study is one of few to have investigated spoken word processing in dyslexic adults, rather than dyslexics' difficulties with phonological awareness or non-word repetition. In line with Schulte-Körne et al. (2001) and Ramus et al. (2003), subtle problems in speech processing in dyslexia were found to persist into adulthood. This clearly affects lexical activation patterns in comprehension of running speech. The finding that differences between the groups could not be discerned on the final mismatch position, but were present in the onset condition, coupled to the correlation between the accuracy and non-word repetition task, points towards a subtle speech processing deficit which is reinforced in case there is no single representation to compare the speech input against. As argued before, having zoomed in on one lexical candidate evidently allows dyslexic participants to direct their attention to a checking procedure to match the incoming speech sounds to one specific representation. Further research could focus on the ease with which people with dyslexia perceive speech in background noise conditions. Given that subtle speech processing problems apparently exist in dyslexia, these problems may show up even clearer in adverse listening conditions (e.g., 
Watson and Miller 1993) or in words or sentences that are articulated less accurately than the isolated words we used here.

Open Access This article is distributed under the terms of the Creative Commons Attribution Noncommercial License which permits any noncommercial use, distribution, and reproduction in any medium, provided the original author(s) and source are credited.

\section{Appendix 1}

See Table 3

Table 3 Complete list of non-word items (stressed syllable is preceded by a stress mark and each mismatch non-word has the word that it is derived from in brackets)

\begin{tabular}{|c|c|c|c|}
\hline \multicolumn{2}{|l|}{ Initial mismatch } & \multicolumn{2}{|l|}{ Final mismatch } \\
\hline Mismatch non-word & Control non-word & Mismatch non-word & Control non-word \\
\hline \multicolumn{4}{|l|}{ Mismatch in unstressed syllable } \\
\hline 1 figa'ret (sigaret) & firè'gat & 21 no'tarig (notaris) & ta'morig \\
\hline 2 bano'rama (panorama) & bama'lona & 22 pan'toffen (pantoffel) & tun'peffen \\
\hline 3 symnas'tiek (gymnastiek) & simtie'snaak & 23 sa'larif (salaris) & lo'soerif \\
\hline 4 sfeku'laas (speculaas) & sfela'kuus & 24 karbo'nabe (karbonade) & durgo'kabe \\
\hline 5 pele'foon (telefoon) & pego'leen & 25 mayo'naite (mayonaise) & nomi'jaite \\
\hline 6 zita'mine (vitamine) & zini'tame & 26 balu'strabe (balustrade) & stubri'labe \\
\hline 7 terso'neel (personeel) & terno'saal & 27 ar'tiker (artikel) & ki'troter \\
\hline 8 banus'cript (manuscript) & baskrit'nup & 28 je’ruzalep (Jeruzalem) & zu’jeurelep \\
\hline 9 rocomo'tief (locomotief) & romieto'rof & 29 hor'love (horloge) & lar'move \\
\hline 10 baral'lel (parallel) & baru'gel & 30 the' atel (theater) & jee'kautel \\
\hline \multicolumn{4}{|l|}{ Mismatches in stressed syllable } \\
\hline 11 'lisico (risico) & 'likosee & 31 bios'coot (bioscoop) & bogi'koot \\
\hline 12 'golibrie (kolibri) & 'goruubla & 32 acro'baak (acrobaat) & tora'baak \\
\hline 13 'faprika (paprika) & 'fakarip & 33 apparte'memp (appartement) & meteppo'memp \\
\hline 14 'finaasappel (sinaasappel) & 'fiepelanno & 34 frikan'den (frikandel) & krafi'den \\
\hline 15 'warbecue (barbecue) & 'warjoekep & 35 boule'vaal (boulevard) & luube’vaal \\
\hline 16 'skadion (stadion) & 'skanodi & 36 neuro'loof (neuroloog) & mazi'loof \\
\hline 17 'droccoli (broccoli) & 'drongila & 37 kroko'dir (krokodil) & geufa'dir \\
\hline 18 'nominee (dominee) & 'nonamo & 38 insti’tuus (instituut) & sepma'tuus \\
\hline 19 'dedminton (badminton) & 'dettonuum & 39 deodo'rank (deodorant) & boosiedee'rank \\
\hline 20 'fenior (senior) & 'feeroju & 40 para'dijt (paradijs) & reupe'dijt \\
\hline
\end{tabular}

\section{Appendix 2}

See Table 4

Table 4 ANOVA analyses on lexical decision accuracy to non-words

\begin{tabular}{lll}
\hline & By-participant analysis & By-item analysis \\
\hline $\begin{array}{l}\text { Participant group (dyslexics, } \\
\text { controls) }\end{array}$ & $F_{1}(1,40)<1, \mathrm{NS}$ & $F_{2}(1,36)<1, \mathrm{NS}$ \\
$\begin{array}{l}\text { Non-word type (mismatch vs. } \\
\text { control) }\end{array}$ & $F_{1}(1,40)=153.6, p<.001$ & $F_{2}(1,36)=7.29, p=.011$ \\
\hline
\end{tabular}


Table 4 continued

\begin{tabular}{|c|c|c|}
\hline & By-participant analysis & By-item analysis \\
\hline $\begin{array}{l}\text { Mismatch position (initial vs. } \\
\text { final) }\end{array}$ & $F_{1}(1,40)=120.40, p<.001$ & $F_{2}(1,36)=3.74, p=.061$ \\
\hline $\begin{array}{l}\text { Metrical salience ( } \mathrm{mm} \text { in } \\
\text { stressed or unstressed } \\
\text { syllable) }\end{array}$ & $F_{1}(1,40)=6.63, p=.014$ & $F_{2}(1,36)<1, \mathrm{NS}$ \\
\hline $\begin{array}{l}\text { Participant } \\
\text { group } \times \text { non-word type }\end{array}$ & $F_{1}(1,40)=3.22, p=.081$ & $F_{2}(1,36)=5.53, p=.024$ \\
\hline $\begin{array}{l}\text { Participant } \\
\text { group } \times \text { mismatch position }\end{array}$ & $F_{1}(1,40)=2.34, \mathrm{NS}$ & $F_{2}(1,36)=3.76, p=.060$ \\
\hline $\begin{array}{l}\text { Participant group } \times \text { metrical } \\
\text { salience }\end{array}$ & $F_{1}(1,40)<1, \mathrm{NS}$ & $F_{2}(1,36)<1, \mathrm{NS}$ \\
\hline $\begin{array}{l}\text { Non-word type } \times \text { mismatch } \\
\text { position }\end{array}$ & $F_{1}(1,40)=145.3, p<.001$ & $F_{2}(1,36)=3.30, p=.078$ \\
\hline $\begin{array}{l}\text { Non-word type } \times \text { metrical } \\
\text { salience }\end{array}$ & $F_{1}(1,40)=18.92, p<.001$ & $F_{2}(1,36)<1, \mathrm{NS}$ \\
\hline $\begin{array}{l}\text { Mismatch position } \times \text { metrical } \\
\text { salience }\end{array}$ & $F_{1}(1,40)=27.93, p<.001$ & $F_{2}(1,36)=1.30, \mathrm{NS}$ \\
\hline $\begin{array}{l}\text { Participant group } \times \text { non-word } \\
\text { type } \times \text { mismatch position }\end{array}$ & $F_{1}(1,40)=8.25, p=.006$ & $F_{2}(1,36)=6.39, p=.016$ \\
\hline $\begin{array}{l}\text { Participant group } \times \text { non-word } \\
\text { type } \times \text { metrical salience }\end{array}$ & $F_{1}(1,40)=3.47, p=.070$ & $F_{2}(1,36)=2.22, \mathrm{NS}$ \\
\hline $\begin{array}{l}\text { Participant group } \times \text { mismatch } \\
\text { position } \times \text { metrical salience }\end{array}$ & $F_{1}(1,40)<1, \mathrm{NS}$ & $F_{2}(1,36)<1, \mathrm{NS}$ \\
\hline $\begin{array}{l}\text { Non-word type } \times \text { mismatch } \\
\text { position } \times \text { metrical salience }\end{array}$ & $F_{1}(1,40)=30.38, p<.001$ & $F_{2}(1,36)<=1.06, \mathrm{NS}$ \\
\hline $\begin{array}{l}\text { Participant group } \times \text { non-word } \\
\text { type } \times \text { mismatch } \\
\text { position } \times \text { metrical salience }\end{array}$ & $F_{1}(1,40)<1, \mathrm{NS}$ & $F_{2}(1,36)<1, \mathrm{NS}$ \\
\hline
\end{tabular}

\section{Appendix 3}

See Table 5

Table 5 ANOVA analyses on response time (1/RT) to non-words

\begin{tabular}{lll}
\hline & By-participant analysis & By-item analysis \\
\hline $\begin{array}{l}\text { Participant group (dyslexics, } \\
\text { controls) } \\
\text { Non-word type (mismatch vs. } \\
\text { control) } \\
\begin{array}{l}\text { Mismatch position (initial vs. } \\
\text { final) }\end{array}\end{array}$ & $F_{1}(1,40)=12.42, p=.001$ & $F_{2}(1,36)=578.67, p<.001$ \\
$\begin{array}{l}\text { Metrical salience (mm in } \\
\text { stressed or unstressed } \\
\text { syllable) }\end{array}$ & $F_{1}(1,40)=155.83, p<.001$ & $F_{2}(1,36)=56.35, p<.001$ \\
$\begin{array}{l}\text { Participant } \\
\text { group } \times \text { non-word type }\end{array}$ & $F_{1}(1,40)=15.76, p<.001$ & $F_{2}(1,36)=2.17, \mathrm{NS}$ \\
$\begin{array}{l}\text { Participant } \\
\text { group } \times \text { mismatch position } \\
\text { Participant group } \times \text { metrical } \\
\text { salience }\end{array}$ & $F_{1}(1,40)=1.82, \mathrm{NS}$ & $F_{2}(1,36)<1, \mathrm{NS}$ \\
\hline
\end{tabular}


Table 5 continued

\begin{tabular}{lll}
\hline & By-participant analysis & By-item analysis \\
\hline $\begin{array}{l}\text { Non-word type } \times \text { mismatch } \\
\text { position }\end{array}$ & $F_{1}(1,40)=15.89, p<.001$ & $F_{2}(1,36)=1.57, \mathrm{NS}$ \\
$\begin{array}{c}\text { Non-word type } \times \text { metrical } \\
\text { salience }\end{array}$ & $F_{1}(1,40)=6.47, p=.015$ & $F_{2}(1,36)=1.37, \mathrm{NS}$ \\
$\begin{array}{l}\text { Mismatch position } \times \text { metrical } \\
\text { salience }\end{array}$ & $F_{1}(1,40)=4.37, p=.043$ & $F_{2}(1,36)<1, \mathrm{NS}$ \\
$\begin{array}{c}\text { Participant group } \times \text { non-word } \\
\text { type } \times \text { mismatch position }\end{array}$ & $F_{1}(1,40)=8.08, p=.007$ & $F_{2}(1,36)=3.94, p=.055$ \\
$\begin{array}{c}\text { Participant group } \times \text { non-word } \\
\text { type } \times \text { metrical salience }\end{array}$ & $F_{1}(1,40)<1, \mathrm{NS}$ & $F_{2}(1,36)<1, \mathrm{NS}$ \\
$\begin{array}{c}\text { Participant group } \times \text { mismatch } \\
\text { position } \times \text { metrical salience }\end{array}$ & $F_{1}(1,40)<1, \mathrm{NS}$ & $F_{2}(1,36)<1, \mathrm{NS}$ \\
$\begin{array}{c}\text { Non-word type } \times \text { mismatch } \\
\text { position } \times \text { metrical salience }\end{array}$ & $F_{1}(1,40)=2.14, \mathrm{NS}$ & $F_{2}(1,36)<1, \mathrm{NS}$ \\
$\begin{array}{c}\text { Participant group } \times \text { non-word } \\
\text { type } \times \text { mismatch } \\
\text { position } \times \text { metrical salience }\end{array}$ & $F_{1}(1,40)=5.70, p=.022$ & $F_{2}(1,36)=3.28, p=.079$ \\
\hline
\end{tabular}

\section{References}

Andruski, J., Blumstein, S., \& Burton, M. (1994). The effect of subphonetic differences on lexical access. Cognition, 52, 163-187.

Blomert, L., Mitterer, H., \& Paffen, C. (2004). In search of the auditory, phonetic, and/or phonological problems in dyslexia: Context effects in speech perception. Journal of Speech Language and Hearing Research, 47, 1030-1047.

Bowey, J. A., \& Hirakis, E. (2006). Testing the protracted lexical restructuring hypothesis: The effects of position and acoustic-phonetic clarity on sensitivity to mispronunciations in children and adults. Journal of Experimental Child Psychology, 95, 1-17.

Breier, J. I., Gray, L., Fletcher, J. M., Diehl, R. L., Klaas, P., Foorman, B. R., \& Molis, M. R. (2001). Perception of voice and tone onset time continua in children with dyslexia with and without attention deficit/hyperactivity disorder. Journal of Experimental Child Psychology, 80, 245-270.

Brus, B. T., \& Voeten, M. J. M. (1973). Een-Minuut-Test. Nijmegen (The Netherlands): Berkhout.

Carroll, J. M., \& Snowling, M. J. (2004). Language and phonological skills in children at high risk of reading difficulties. Journal of Child Psychology and Psychiatry, 45, 631-640.

Cole, R. A. (1973). Listening for mispronunciations: A measure of what we hear during speech. Perception and Psychophysics, 1, 153-156.

Connine, C. M. (1994). Vertical and horizontal similarity in spoken word recognition. In C. Clifton, Jr, L. Fraizier, \& K. Rayner, Perspectives on sentence processing. Hillsdale (NJ): Lawrence Erlbaum Associates Inc.

Connine, C. M., Titone, D. A., Deelman, T., \& Blasko, D. (1997). Similarity mapping in spoken word recognition. Journal of Memory and Language, 37, 463-480.

Cooper, R. M. (1974). The control of eye fixation by the meaning of spoken language: A new methodology for the real-time investigation of speech perception, memory, and language processing. Cognitive Psychology, 6, 84-107.

De Bree, E., Rispens, J., \& Gerrits, E. (2007). Non-word repetition in Dutch children with (a risk of) dyslexia and SLI. Clinical Linguistics and Phonetics, 21, 935-944.

De Bree, E., van Alphen, P., Fikkert, P., \& Wijnen F. (2008). Metrical stress in comprehension and production of Dutch children at risk of dyslexia. In: H. Chan, H. Jacob, Kapia (Eds.), BUCLD 32 proceedings (pp. 60-71).

De Jong, P. F. (1998). Working memory deficits of reading disabled children. Journal of Experimental Child Psychology, 70, 75-96.

Felton, R. H., Naylor, C. E., \& Wood, B. E. (1990). Neuropsychological profile of adult dyslexics. Brain and Language, 39, 485-497.

Frauenfelder, U. H., Scholten, M., \& Content, A. (2001). Bottom-up inhibition in lexical selection: Phonological mismatch effects in spoken word recognition. Language and Cognitive Processes, 16, 583-607. 
Gaskell, M. G., \& Marslen-Wilson, W. D. (1997). Integrating form and meaning: A distributed model of speech perception. Language and Cognitive Processes, 12, 613-656.

Hazan, V., Messaoud-Galussi, S., Rosen, S., Nouwens, S., \& Shakespeare, B. (2009). Speech perception abilities of adults with dyslexia: Is there any evidence for a true deficit? Journal of Speech, Language and Hearing Research, 52, 1510-1529.

Janse, E. (2010). Spoken word processing and the effect of phonemic mismatch in aphasia. Aphasiology, 24, 3-27.

Janse, E., Nooteboom, S. G., \& Quené, H. (2007). Coping with gradient forms of /t/-deletion and lexical ambiguity in spoken word recognition. Language and Cognitive Processes, 22, 161-200.

Kuijpers, C., van der Leij, A., Been, P., van Leeuwen, Y., ter Keurs, M., Schreuder, R., \& van den Bos, K. P. (2003). Leesproblemen in het voortgezet onderwijs en de volwassenheid. Pedagogische Studiën, 80, 272-287.

Luce, P. A., \& Pisoni, D. B. (1998). Recognizing spoken words: The neighborhood activation model. Ear and Hearing, 19, 1-36.

Lyon, G. R. (1995). Toward a definition of dyslexia. Annals of Dyslexia, 45, 3-27.

Manis, F. R., McBride-Chang, C., Seidenberg, M. S., Keating, D., Doi, L. M., Munson, G., \& Peterson, A. (1997). Are speech perception deficits associated with developmental dyslexia? Journal of Experimental Child Psychology, 66, 211-235.

Marslen-Wilson, W. D. (1985). Speech shadowing and speech comprehension. Speech Communication, 4, 55-73.

Martin, N., \& Gupta, P. (2004). Exploring the relationship between word processing and verbal short-term memory: Evidence from associations and dissociations. Cognitive Neuropsychology, 21, 213-228.

McArthur, G. M., Ellis, D., Atkinson, C. M., \& Coltheart, M. (2008). Auditory processing deficits in children with reading and language impairments: Can they (and should they) be treated? Cognition, 107, 946-977.

Metsala, J. L. (1997). Spoken word recognition in reading disabled children. Journal of Educational Psychology, 89, 159-169.

Metsala, J. L., \& Walley, A. C. (1998). Spoken vocabulary growth and the segmental restructuring of lexical representations: Precursors to phonemic awareness and early reading ability. In J. L. Metsala \& L. C. Ehri (Eds.), Word recognition in beginning literacy (pp. 89-120). Mahwah (NJ): Lawrence Erlbaum Associates.

Mitterer, H., \& Ernestus, M. (2006). Listeners recover /t/s that speakers reduce: Evidence from /t/-lenition in Dutch. Journal of Phonetics, 34, 73-103.

Mody, M., Studdert-Kennedy, M., \& Brady, S. (1997). Speech perception deficits in poor readers: Auditory processing or phonological coding? Journal of Experimental Child Psychology, 64, 199-231.

Motta, G., Rizzo, F., Swinney, D., \& Piñango, M. M. (2000). Tempo: A software for psycholinguistic and neuroimaging testing. Brandeis University (Dept of Computer Science), University of California San Diego (Dept of Psychology) and Yale University (Department of Linguistics).

Muter, V., \& Snowling, M. J. (1998). Concurrent and longitudinal predictors of reading: The role of metalinguistic and short-term memory skills. Reading Research Quarterly, 33, 320-337.

Nittrouer, S. (1999). Do temporal processing deficits cause phonological problems? Journal of Speech Language and Hearing Research, 42, 925-942.

Norris, D. (1994). Shortlist: A connectionist model of continuous speech recognition. Cognition, 52, 189-234.

Paulesu, E., Frith, U., Snowling, M., Gallagher, A., Morton, J., Frackowiak, F. S. J., \& Frith, C. D. (1996). Is developmental dyslexia a disconnection syndrome? Evidence from PET scanning. Brain, 119, 143-157.

Paulesu, E., Demonet, J. F., Fazio, F., McCrory, E., Chanoine, V., Brunswick, N., Cappa, S. F., Cossu, G., Habib, M., Frith, C. D., \& Frith, U. (2001). Cultural diversity and biological unity. Science, 291, 21652167.

Pennington, B. F., Van Orden, G. C., Smith, S. D., Green, P. A., \& Haith, M. M. (1990). Phonological processing skills and deficits in adult dyslexics. Child Development, 61, 1753-1778.

Ramus, F. (2003). Developmental dyslexia: Specific phonological deficit or general sensorimotor dysfunction? Current Opinion in Neurobiology, 13, 212-218.

Ramus, F., Rosen, S., Dakin, S. C., Day, B. L., Castellote, J. M., White, S., \& Frith, U. (2003). Theories of developmental dyslexia: Insights from a multiple case study of dyslexic adults. Brain, 126, 841-865.

Ramus, F., \& Szenkovits, G. (2008). What phonological deficit? Quarterly Journal of Experimental Psychology, 61, 129-141.

Roodenrys, S., \& Stokes, J. (2001). Serial recall and nonword repetition in reading disabled children. Reading and Writing, 14, 379-394.

Rosen, S. (2003). Auditory processing in dyslexia and specific language impairment: is there a deficit? What is its nature? Does it explain anything? Journal of Phonetics, 31, 509-527. 
Salverda, A. P., Dahan, D., \& McQueen, J. M. (2003). The role of prosodic boundaries in the resolution of lexical embedding in speech comprehension. Cognition, 90, 51-89.

Samuel, A. G. (1987). Lexical uniqueness effects on phonemic restoration. Journal of Memory and Language, 26, 36-56.

Schulte-Körne, G., Deimel, W., Bartling, J., \& Remschmidt, H. (2001). Speech perception deficit in dyslexic adults as measured by mismatch negativity (MMN). International Journal of Psychophysiology, 40, 77-87.

Shatzman, K. B., \& McQueen, J. M. (2006). Segment duration as a cue to word boundaries in spoken-word recognition. Perception and Psychophysics, 68, 1-16.

Serniclaes, W., Sprenger-Charolles, L., Carré, R., \& Démonet, J.-F. (2001). Perceptual discrimination of speech sounds in dyslexics. Journal of Speech Language and Hearing Research, 44, 384-399.

Snowling, M., Goulandris, A., Bowlby, M., \& Howell, P. (1986). Segmentation and speech perception in relation to reading skill: A developmental analysis. Journal of Experimental Child Psychology, 41, 489-507.

Snowling, M. J. (2001). From language to reading to dyslexia. Dyslexia, 7, 37-46.

Spinelli, E., McQueen, J. M., \& Cutler, A. (2003). Processing resyllabified words in French. Journal of Memory and Language, 48, 233-254.

Sutcliffe, P. A., Bishop, D. V. M., Houhgton, S., \& Taylor, M. (2006). Effect of attentional state on frequency discrimination: A comparison of children with ADHD on and off medication. Journal of Speech Language and Hearing Research, 49, 1072-1084.

Szenkovits, G., \& Ramus, F. (2005). Exploring dyslexics' phonological deficit I: Lexical vs. sub-lexical and input vs. output processes. Dyslexia, 11, 253-268.

Talcott, J. B., Witton, C., Hebb, G. S., Stoodley, C. J., Westwood, E. A., France, S. J., Hansen, P. C., \& Stein, J. F. (2002). On the relationship between dynamic visual and auditory processing and literacy skills; results from a large primary-school study. Dyslexia, 8, 204-225.

Tallal, P. (1980). Auditory temporal perception, phonetics, and reading disabilities in children. Brain and Language, 9, 182-198.

Tallal, P. (1984). Temporal or phonetic processing deficit in dyslexia? That's the question. Applied Psycholinguistics, 5, 167-169.

Tanenhaus, M. K., Spivey-Knowlton, M. J., Eberhard, K. M., \& Sedivy, J. C. (1995). Integration of visual and linguistic information in spoken language comprehension. Science, 268, 1632-1634.

Van Alphen, P., de Bree, E., Gerrits, E., de Jong, J., Wilsenach, C., \& Wijnen, F. (2004). Early language development in children with a genetic risk of dyslexia. Dyslexia, 10, 265-288.

Van den Bos, K. P., Spelberg, H. C. L, Scheepstra, A. J. M., \& de Vries, J. R. (1994). De KLEPEL. Een test voor de leesvaardigheid van pseudo-woorden. Nijmegen: Berkhout Testmateriaal.

Vellutino, F. R., Fletcher, J. M., Snowling, M. J., \& Scanlon, D. (2004). Specific reading disability (dyslexia): What have we learned in the past four decades? Journal of Child Psychology and Psychiatry, 45, 2-40.

Vitevitch, M. S., \& Luce, P. A. (1999). Probabilistic phonotactics and neighborhood activation in spoken word recognition. Journal of Memory and Language, 40, 374-408.

Warren, R. M. (1970). Restoration of missing speech sounds. Science, 167, 392-393.

Watson, B. U., \& Miller, T. K. (1993). Auditory perception, phonological processing and reading ability/disability. Journal of Speech and Hearing Research, 36, 850-863.

Wechsler, D. (2000). Wechsler Adult Intelligence Scale WAIS-III-NL. Nederlandstalige bewerking. In Uterwijk, J. M. (Ed.), Lisse (the Netherlands): Swets and Zeitlinger. Herziene technische handleiding 2005. Amsterdam: Harcourt Test Publishers. 